\title{
Best practice guidelines regarding diagnosis and management of patients with type II collagen disorders
}

\author{
Ravi Savarirayan, MBBS, MD ${ }^{1}{ }^{1}$, Viviana Bompadre, $\mathrm{PhD}^{2}$, Michael B. Bober, MD PhD ${ }^{3}$, \\ Tae-Joon Cho, MD ${ }^{4}$, Michael J. Goldberg, $\mathrm{MD}^{5}$, Julie Hoover-Fong, MD PhD ${ }^{6}$, Melita Irving, $\mathrm{MD}^{7}$, \\ Shawn E. Kamps, $\mathrm{MD}^{8}$, William G. Mackenzie, $\mathrm{MD}^{9}$, Cathleen Raggio, $\mathrm{MD}^{10}$, \\ Samantha S. Spencer, MD ${ }^{11}$ and \\ Klane K. White, MD ${ }^{5}$ on behalf of the Skeletal Dysplasia Management Consortium
}

Purpose: Skeletal dysplasias comprise a heterogeneous group of inherited disorders of development, growth, and maintenance of the human skeleton. Because of their relative rarity and wide phenotypic variability, patients should be accurately identified, uniformly assessed, and managed by clinicians who are aware of their potential complications and possess the knowledge and resources to treat them effectively. This study presents expert guidelines developed to improve the diagnosis and management of patients with type II collagen skeletal disorders to optimize clinical outcomes.

Methods: A panel of 11 multidisciplinary international experts in the field of skeletal dysplasia participated in a Delphi process, which comprised analysis of a thorough literature review with subsequent generation of 26 diagnosis and care recommendations, followed by two rounds of anonymous voting with an intervening face-to-face meeting. Those recommendations with more than $80 \%$ agreement were considered as consensual. Results: After the first voting round, consensus was reached to support 12 of $26(46 \%)$ statements. After the panel discussion, the group reached consensus on 22 of 24 revised statements (92\%).

Conclusions: Consensus-based, expert best practice guidelines developed as a standard of care to assist accurate diagnosis, minimize associated health risks, and improve clinical outcomes for patients with type II collagen skeletal dysplasias.

Genetics in Medicine (2019) 21:2070-2080; https://doi.org/10.1038/s41436019-0446-9

Keywords: type II collagen disorder; skeletal dysplasia; management; best practice guidelines; Delphi process

\section{INTRODUCTION}

The skeletal dysplasias comprise a large, heterogeneous, and collectively common group of inherited disorders that affect development, growth, and maintenance of cartilage and bone. ${ }^{1}$ Variants in the gene encoding type II collagen (COL2A1) give rise to a variety of clinical phenotypes ranging from severe perinatal lethal disorders that present antenatally to milder conditions that present in the postnatal period and childhood. The hallmarks of classic type II collagen disorders include disproportionate short stature, skeletal dysplasia, distinctive eye abnormalities, cleft palate, small jaw, and hearing loss, however, there is remarkable variability in disease presentation, and the clinical spectrum of COL2A1 variants extends from perinatal lethal to isolated joint disease (arthritis). These expert guidelines aim to make relevant health-care professionals aware of these rare conditions, and their associated clinical manifestations, to assist them in optimizing patient outcomes through best" practice, including medical and surgical management, and genetic counseling.

\section{MATERIALS AND METHODS}

A RAND-UCLA modified Delphi method was used to create consensus-based guidelines for the treatment and management of patients with type II collagen disorders. This methodology consists of a systematic literature review, creation of a list of statements, multiple rounds vetting those statements, and a face-to-face meeting where these indications are rated anonymously by a group of experts. ${ }^{2,3}$ The group of

\footnotetext{
${ }^{1}$ Victorian Clinical Genetics Services, Murdoch Children's Research Institute, University of Melbourne, VIC, Parkville, Australia; ${ }^{2}$ Department of Orthopedics and Sports Medicine, Seattle Children's Hospital, Seattle, WA, USA; ${ }^{3}$ Division of Genetics, Nemours A.I. duPont Hospital for Children, Wilmington, DE, USA; ${ }^{4}$ Division of Pediatric Orthopaedics, Seoul National University Children's Hospital, Seoul, South Korea; ${ }^{5}$ Department of Orthopedics and Sports Medicine, Seattle Children's Hospital, University of Washington, Seattle, WA, USA; ${ }^{6}$ McKusick-Nathans Institute of Genetic Medicine, Johns Hopkins University, Baltimore, MD, USA; ${ }^{7}$ Department of Clinical Genetics, Guy's and St Thomas NHS, London, UK; ${ }^{8}$ Department of Radiology, Seattle Children's Hospital, University of Washington, Seattle, WA, USA; ${ }^{9}$ Department of Orthopedic Surgery, Nemours A.I. duPont Hospital for Children, Wilmington, DE, USA; ${ }^{10}$ Department of Orthopedic Surgery, Hospital for Special Surgery, New York, NY, USA; ${ }^{11}$ Department of Orthopedic Surgery, Boston Children's Hospital, Boston, MA, USA. Correspondence: Ravi Savarirayan (ravi.savarirayan@vcgs.org.au)
} 
clinicians who participated in this study have an average 20 years of experience in treating patients with type II collagen disorders (range 13-43 years), and manage over 500 patients with these conditions. The Delphi methodology has been widely used in medical research to determine appropriate treatment and best practice guidelines, ${ }^{4-6}$ and has been successfully used by this group previously. ${ }^{7-9}$

The primary author (R.S.) created statements based on systematic literature review that were evaluated by the authors who edited the list. The first electronic survey consisted of 26 statements and was distributed with the referenced literature search to a panel of international experts in September 2017 (round 1) (Table 1). Respondents rated the statements using a 5-point Likert scale (Strongly Agree, Agree, Neutral, Disagree, and Strongly Disagree). A month later, at a face-to-face meeting, the results of the survey and the literature review were presented. Structured discussion was focused on areas of disagreement with the opportunity to modify statements if desired. The panel then suggested edits and the revised statements were rated anonymously for a second time by electronic survey (round 2).

Consensus of $80 \%$ is considered the standard for Delphi processes, and this percentage was agreed to a priori. Statements with $\geq 80 \%$ agreement between two categories (Strongly Agree and Agree, or Strongly Disagree and Disagree) were interpreted as appropriate or inappropriate and included in the guidelines. The panel consisted of 11 international experts on skeletal dysplasia comprising 6 pediatric orthopedic surgeons, 4 medical geneticists, and 1 pediatric radiologist.

\section{RESULTS}

In round 1, the panel agreed on 12 of 26 statements (Table $\mathbf{1}$ ). Statements not reaching 80\% agreement are listed in Table 2. During the face-to-face meeting, the list was modified into 24 statements and rated again (round 2), where 22 statements reached $\geq 80 \%$ consensus (Tables 3 ) and 2 statements did not (Table 4).

The Delphi process substantially increased consensus for modified statements and a list of 22 best practice guidelines was generated (Table 3 and Discussion). After review of results, all participants agreed to support its publication.

\section{DISCUSSION}

\section{Type II collagen disorders present with a wide range of phenotypic variability}

The phenotypic spectrum caused by variants in type II collagen is wide, and a high index of suspicion is required if these conditions are to be recognized and managed. Type II collagen is present in the developing cartilage anlagen and is essential for endochondral ossification. Abnormalities of type II collagen result in a spectrum of autosomal dominant skeletal dysplasias that can present to a wide variety of health-care professionals. ${ }^{1}$ These range from perinatally lethal conditions with significant long bone shortening and a small chest to relatively mild entities that may be apparent

Table 1 First round statements with $\geq 80 \%$ agreement

\begin{tabular}{|c|c|c|c|c|c|}
\hline & $\begin{array}{l}\text { Strongly } \\
\text { agree }\end{array}$ & Agree & Neutral & Disagree & $\begin{array}{l}\text { Strongly } \\
\text { disagree }\end{array}$ \\
\hline $\begin{array}{l}\text { 1. Type II collagen disorders present with a wide range of phenotypic } \\
\text { variability }\end{array}$ & $10(90.9 \%)$ & $1(9.1 \%)$ & 0 & 0 & 0 \\
\hline $\begin{array}{l}\text { 2. Commonly recognized phenotypes of type II collagen disorders include } \\
\text { spondyloepiphyseal dysplasia congenita, Kniest dysplasia, Stickler syndrome } \\
\text { type I, hypochondrogenesis, achondrogenesis type ॥ }\end{array}$ & $7(63.6 \%)$ & $4(36.4 \%)$ & 0 & 0 & 0 \\
\hline $\begin{array}{l}\text { 3. Diagnostic clues to type II collagen disorders include disproportionate short } \\
\text { stature, radiographic spondyloepiphyseal dysplasia, palate abnormalites, } \\
\text { myopia, and hearing loss }\end{array}$ & $6(54.5 \%)$ & $4(36.4 \%)$ & $1(9.1 \%)$ & 0 & 0 \\
\hline $\begin{array}{l}\text { 4. Type II collagen disorders can present in the prenatal period with lack of } \\
\text { ossification of the skeleton }\end{array}$ & $6(54.5 \%)$ & $4(36.4 \%)$ & 0 & 0 & $1(9.1 \%)$ \\
\hline $\begin{array}{l}\text { 6. Neonates who present with Robin sequence should have detailed eye and } \\
\text { audiological examination, looking for features of Stickler syndrome }\end{array}$ & $5(45.5 \%)$ & $5(45.5 \%)$ & 0 & $1(9.1 \%)$ & 0 \\
\hline $\begin{array}{l}\text { 7. Children with type II collagen disorders may have average stature (Stickler, } \\
\text { Czech) }\end{array}$ & $5(45.5 \%)$ & $6(54.5 \%)$ & 0 & 0 & 0 \\
\hline 11. Routine monitoring by an ophthalmologist is recommended & $6(54.5 \%)$ & $4(36.4 \%)$ & $1(9.1 \%)$ & 0 & 0 \\
\hline 12. Retinal detachment is common in type II collagen disorders & $5(45.5 \%)$ & $4(36.4 \%)$ & $1(9.1 \%)$ & $1(9.1 \%)$ & 0 \\
\hline 13. Myopia is a common feature of type II collagen disorders & $7(63.6 \%)$ & $4(36.4 \%)$ & 0 & 0 & 0 \\
\hline $\begin{array}{l}\text { 16. Routine monitoring for cervical instability with flexion-extension } \\
\text { radiographs should be performed }\end{array}$ & $7(63.6 \%)$ & $4(36.4 \%)$ & 0 & 0 & 0 \\
\hline 18. Routine monitoring for hearing loss is recommended & $5(45.5 \%)$ & $5(45.5 \%)$ & 0 & $1(9.1 \%)$ & 0 \\
\hline 20. Precocious arthritis is common in patients with type II collagen disorders & $5(45.5 \%)$ & $5(45.5 \%)$ & 0 & $1(9.1 \%)$ & 0 \\
\hline
\end{tabular}


Table 2 First round statements with $<80 \%$ agreement

\begin{tabular}{|c|c|c|c|c|c|}
\hline & Strongly agree & Agree & Neutral & Disagree & Strongly disagree \\
\hline $\begin{array}{l}\text { 5. In the neonate, coronal vertebral clefting and coronal clefting of the } \\
\text { foramen magnum is highly specific for type II collagen disorders }\end{array}$ & $1(9.1 \%)$ & $6(54.5 \%)$ & $1(9.1 \%)$ & $3(27.3 \%)$ & 0 \\
\hline $\begin{array}{l}\text { 8. Human growth hormone supplementation is appropriate for } \\
\text { children with type II collagen disorders }\end{array}$ & 0 & 0 & $3(27.3 \%)$ & $4(36.4 \%)$ & $4(36.4 \%)$ \\
\hline $\begin{array}{l}\text { 9. Routine cardiac evaluation and surveillance should be pursued in all } \\
\text { patients with type II collagen disorders }\end{array}$ & $1(9.1 \%)$ & $2(18.2 \%)$ & $3(27.3 \%)$ & $4(36.4 \%)$ & $1(9.1 \%)$ \\
\hline $\begin{array}{l}\text { 10. The incidence of significant respiratory disease is higher in } \\
\text { individuals with type II collagen disorders, especially those with SEDC }\end{array}$ & $2(18.2 \%)$ & $6(54.5 \%)$ & $2(18.2 \%)$ & $1(9.1 \%)$ & 0 \\
\hline $\begin{array}{l}\text { 14. Patients with Stickler syndrome and confirmed COL2A1 variant } \\
\text { should have prophylactic retinopexy }\end{array}$ & 0 & $3(27.3 \%)$ & $6(54.5 \%)$ & $2(18.2 \%)$ & 0 \\
\hline $\begin{array}{l}\text { 15. Cervical instability is common in SEDC, often requiring surgical } \\
\text { intervention }\end{array}$ & $6(54.5 \%)$ & $2(18.2 \%)$ & 0 & $3(27.3 \%)$ & 0 \\
\hline 17. Routine monitoring with MRI of the spine is recommended & 0 & $2(18.2 \%)$ & $4(36.4 \%)$ & $4(36.4 \%)$ & $1(9.1 \%)$ \\
\hline $\begin{array}{l}\text { 19. Patients with the appearance of bilateral Legg-Calvé-Perthes } \\
\text { disease should be evaluated for a type II collagen disorder }\end{array}$ & $2(18.2 \%)$ & $6(54.5 \%)$ & $2(18.2 \%)$ & $1(9.1 \%)$ & 0 \\
\hline $\begin{array}{l}\text { 21. Joint arthroplasty is a beneficial surgery for young adults with } \\
\text { precocious arthritis of the hip and knees }\end{array}$ & $3(27.3 \%)$ & $3(27.3 \%)$ & $4(36.4 \%)$ & $1(9.1 \%)$ & 0 \\
\hline $\begin{array}{l}\text { 22. Coxa vara is common in children with SEDC and valgus/extension } \\
\text { osteotomy can improve gait }\end{array}$ & $4(36.4 \%)$ & $3(27.3 \%)$ & $4(36.4 \%)$ & 0 & 0 \\
\hline 23. Genu valgum is common in children with type II collagen disorders & $2(18.2 \%)$ & $6(54.5 \%)$ & $1(9.1 \%)$ & $2(18.2 \%)$ & 0 \\
\hline $\begin{array}{l}\text { 24. Guided growth techniques are useful in the treatment of genu } \\
\text { valgum in children with type II collagen disorders }\end{array}$ & $2(18.2 \%)$ & $6(54.5 \%)$ & $3(27.3 \%)$ & 0 & 0 \\
\hline $\begin{array}{l}\text { 25. Because stiffness in the finger joints is common in some type II } \\
\text { collagen disorders, and because enzyme replacement therapy is } \\
\text { available, testing for Morquio or other MPS may be considered }\end{array}$ & $1(9.1 \%)$ & $5(45.5 \%)$ & $1(9.1 \%)$ & $4(36.4 \%)$ & 0 \\
\hline $\begin{array}{l}\text { 26. Because of the early onset of joint pain and/or marked restricted } \\
\text { joint ROM in type II collagen disorders, consideration of power scooters } \\
\text { in young children is recommended }\end{array}$ & $3(27.3 \%)$ & $5(45.5 \%)$ & 0 & $3(27.3 \%)$ & 0 \\
\hline
\end{tabular}

only in later childhood and adulthood. ${ }^{10,11}$ These conditions are hallmarked by disproportionate short stature, eye abnormalities that can predispose to retinal detachment and blindness, cleft palate with jaw hypoplasia (Pierre Robin sequence $[\mathrm{PRS}]$ ), and hearing loss. Some type II collagen (COL2A1) disorders may manifest as premature degenerative joint disease in the absence of other typical phenotypic clues and mimic osteoarthritis. ${ }^{10}$

The importance of accurate diagnosis of a COL2A1related bone disorder is the subsequent ability to accurately assess recurrence risks and offer information regarding disease natural history. It enables at-risk individuals to be identified for implementation of emerging preventive strategies (such as prophylactic retinopexy to mitigate the incidence of retinal detachment) and early ameliorative management. Such interventions can translate to a reduction in personal and public health burdens associated with these musculoskeletal diseases. The prevalence figure for type II collagenopathies as a group is not known but Stickler syndrome, the most common, is estimated at 1/10,000 (ref. ${ }^{12}$ ).

\section{Recognized skeletal phenotypes of type II collagen disorders include (from most to least severe): achondrogenesis type II, hypochondrogenesis, Kniest dysplasia, spondyloepiphyseal dysplasia congenita (SEDC),}

\section{Stickler syndrome type I, and mild SED with premature arthrosis}

Achondrogenesis type II, the most severe, is antenatally lethal, associated with severe deficiency of ossification and extreme skeletal dysplasia resulting in micromelia, narrow chest with pulmonary hypoplasia, and PRS. Hypochondrogenesis has similar phenotype, with less severe skeletal involvement and is usually lethal. Kniest dysplasia represents the most severe type II collagen disorder resulting in live birth. The skeletal features are more severe than spondyloepiphyseal dysplasia congenita (SEDC), with more pronounced abnormalities of bone modeling and vertebral clefting, absence of significant brachydactyly, and long-term joint problems, although there can be wide phenotypic variability. Respiratory complications, such as tracheolaryngomalacia, are also observed in these two conditions, as is PRS, which is also a characteristic feature of type I Stickler syndrome, where stature is normal and 
Table 3 Second round statements with $\geq 80 \%$ agreement: final guidelines

\begin{tabular}{|c|c|c|c|c|c|}
\hline & $\begin{array}{l}\text { Strongly } \\
\text { agree }\end{array}$ & Agree & Neutral & Disagree & $\begin{array}{l}\text { Strongly } \\
\text { disagree }\end{array}$ \\
\hline 1. Type II collagen disorders present with a wide range of phenotypic variability & $11(100 \%)$ & 0 & 0 & 0 & 0 \\
\hline $\begin{array}{l}\text { 2. Recognized skeletal phenotypes of type II collagen disorders include (in order } \\
\text { of decreasing severity): achondrogenesis type II, hypochondrogenesis, Kniest } \\
\text { dysplasia, spondyloepiphyseal dysplasia congenita (SEDC), Stickler syndrome type } \\
\text { I, mild SED with premature onset arthrosis }\end{array}$ & $11(100 \%)$ & 0 & 0 & 0 & 0 \\
\hline $\begin{array}{l}\text { 3. Diagnostic clues to type II collagen disorders include disproportionate short } \\
\text { stature, radiographic spondyloepiphyseal dysplasia, palate abnormalities, myopia, } \\
\text { and hearing loss }\end{array}$ & $9(81.82 \%)$ & $2(18.18 \%)$ & 0 & 0 & 0 \\
\hline $\begin{array}{l}\text { 4. Type II collagen disorders can present in the prenatal period with lack of } \\
\text { expected ossification of the skeleton }\end{array}$ & $8(72.73 \%)$ & $3(27.27 \%)$ & 0 & 0 & 0 \\
\hline $\begin{array}{l}\text { 5. In the term neonate, coronal vertebral clefting, occipital defect posterior to the } \\
\text { foramen magnum, absent distal femoral epiphyseal ossification, and absent } \\
\text { ossification of the pubis are suggestive of type II collagen disorders }\end{array}$ & $8(72.73 \%)$ & $3(27.27 \%)$ & 0 & 0 & 0 \\
\hline $\begin{array}{l}\text { 7. Neonates who present with Robin sequence should have detailed eye and } \\
\text { audiological examination, looking for features of a type II collagen disorder, such } \\
\text { as Stickler syndrome }\end{array}$ & $10(90.91 \%)$ & $1(9.09 \%)$ & 0 & 0 & 0 \\
\hline $\begin{array}{l}\text { 8. Children with type II collagen disorders may have average stature (Stickler, } \\
\text { Czech) }\end{array}$ & $6(60 \%)$ & $4(40 \%)$ & 0 & 0 & 0 \\
\hline $\begin{array}{l}\text { 9. There is no evidence that human growth hormone supplementation in children } \\
\text { with type II collagen disorders increases final height }\end{array}$ & $9(81.82 \%)$ & $2(18.18 \%)$ & & & \\
\hline $\begin{array}{l}\text { 10. Routine cardiac evaluation and surveillance (i.e., EKG, echocardiogram) is not } \\
\text { indicated in patients with type II collagen disorders }\end{array}$ & $1(9.09 \%)$ & $10(90.91 \%)$ & 0 & 0 & 0 \\
\hline $\begin{array}{l}\text { 11. Significant respiratory problems are common in individuals with type II } \\
\text { collagen disorders and need to be evaluated at all ages }\end{array}$ & $3(27.27 \%)$ & $6(54.55 \%)$ & $1(9.09 \%)$ & $1(9.09 \%)$ & 0 \\
\hline $\begin{array}{l}\text { 12. Routine evaluation and surveillance by an ophthalmologist is necessary } \\
\text { because the risk of retinal detachment and severe myopia are increased in type II } \\
\text { collagen disorders }\end{array}$ & $10(90.91 \%)$ & $1(9.09 \%)$ & 0 & 0 & 0 \\
\hline $\begin{array}{l}\text { 14. Routine imaging and surveillance of the cervical spine is required in some type } \\
\text { II collagen disorders (e.g., SEDC and Kniest) due to increased risk for instability } \\
\text { and spinal cord compression. Imaging may include flexion-extension radiographs } \\
\text { and MRI }\end{array}$ & $10(90.91 \%)$ & $1(9.09 \%)$ & 0 & 0 & 0 \\
\hline $\begin{array}{l}\text { 15. Progressive kyphoscoliosis can occur in children with type II collagen disorders } \\
\text { and should be clinically and radiographically monitored }\end{array}$ & $7(63.64 \%)$ & $4(36.36 \%)$ & 0 & 0 & 0 \\
\hline $\begin{array}{l}\text { 16. Routine evaluation and surveillance for hearing loss is indicated in patients } \\
\text { with type II collagen disorders }\end{array}$ & $8(72.73 \%)$ & $3(27.27 \%)$ & 0 & 0 & 0 \\
\hline $\begin{array}{l}\text { 17. Patients with type II collagen disorders may present with the appearance of } \\
\text { bilateral Legg-Calvé-Perthes disease }\end{array}$ & $6(54.55 \%)$ & $5(45.45 \%)$ & 0 & 0 & 0 \\
\hline 18. Patients with type II collagen disorders may present with early-onset arthritis & $9(81.82 \%)$ & $2(18.18 \%)$ & 0 & 0 & 0 \\
\hline $\begin{array}{l}\text { 19. In type II collagen disorders, hip replacement can be a beneficial surgery for } \\
\text { adolescents and young adults with early-onset arthritis }\end{array}$ & $6(54.55 \%)$ & $5(45.45 \%)$ & 0 & 0 & 0 \\
\hline $\begin{array}{l}\text { 20. In type II collagen disorders with disproportionate short stature, coxa vara and } \\
\text { genu valgum are frequently present }\end{array}$ & $9(81.82 \%)$ & $2(18.18 \%)$ & 0 & 0 & 0 \\
\hline $\begin{array}{l}\text { 21. Valgus extension/internal rotation osteotomy can improve gait in patients } \\
\text { with coxa vara and type II collagen disorders }\end{array}$ & $4(36.36 \%)$ & $7(63.64 \%)$ & 0 & 0 & 0 \\
\hline $\begin{array}{l}\text { 22. Guided growth techniques (if sufficient growth remains) and realignment } \\
\text { osteotomies are effective in the treatment of severe genu valgum in children with } \\
\text { type II collagen disorders }\end{array}$ & $7(63.64 \%)$ & $3(27.27 \%)$ & $1(9.09 \%)$ & 0 & 0 \\
\hline $\begin{array}{l}\text { 23. In patients with clinical or radiographic features of a type II collagen disorder, } \\
\text { molecular testing should be done to confirm diagnosis, allowing accurate } \\
\text { recurrence risk counseling, prenatal diagnosis, and appropriate treatment options } \\
\text { where available }\end{array}$ & $7(63.64 \%)$ & $3(27.27 \%)$ & $1(9.09 \%)$ & 0 & 0 \\
\hline $\begin{array}{l}\text { 24. To promote socialization and independence, individuals with type II collagen } \\
\text { disorders should be assessed for a mobility device for community distances }\end{array}$ & $3(27.27 \%)$ & $8(72.73 \%)$ & 0 & 0 & 0 \\
\hline
\end{tabular}

EKG electrocardiogram, MRI magnetic resonance imaging.

Table 4 Second round statements with $<80 \%$ agreement

\begin{tabular}{|c|c|c|c|c|c|}
\hline & Strongly agree & Agree & Neutral & Disagree & Strongly disagree \\
\hline $\begin{array}{l}\text { 6. Hypochondrogenesis is uniformly lethal during the perinatal } \\
\text { period }\end{array}$ & 0 & $3(27.27 \%)$ & $4(36.36 \%)$ & $3(27.27 \%)$ & $1(9.09 \%)$ \\
\hline $\begin{array}{l}\text { 13. Patients with Stickler syndrome and confirmed COL } 2 A 1 \\
\text { variant should be considered for prophylactic retinopexy }\end{array}$ & $1(9.09 \%)$ & $7(63.64 \%)$ & $3(27.27 \%)$ & 0 & 0 \\
\hline
\end{tabular}

respiratory issues are not usually seen. Mild SED with premature onset arthrosis is the mildest condition, with early-onset degenerative arthritis often necessitating joint replacement before age 50 years. ${ }^{13}$

This spectrum of severity can be explained by the level of disruption to type II collagen fibers, normally incorporated into a triple helical structure. Qualitative abnormalities of this protein result in more severe phenotypes and quantitative anomalies in the milder conditions. Mechanistically, nonsense variants in COL2A1 gene result in haploinsufficiency through nonsense mediated decay of the truncated protein, whereas missense variants, typically glycine substitutions, result in full 
expression of a disordered triple helix with fundamentally disrupted function (dominant negative mechanism). ${ }^{14,15}$

\section{Diagnostic clues to type II collagen disorders include disproportionate short stature, radiographic spondyloepiphyseal dysplasia, palate abnormalities, myopia, and hearing loss}

Type II collagen is present in the skeleton, eyes, orofacial structures, and auditory system. ${ }^{14}$ Key clinical features that point to a possible underlying type II collagen disorder include a small jaw, cleft palate, flat midface, visual or hearing impairment, and variable radiographic changes. A complete skeletal survey is essential for the diagnosis of most type II collagenopathies. These conditions should be considered in the differential diagnosis of individuals presenting with radiographic evidence of vertebral body and epiphyseal dysplasia, especially when accompanied by ocular, orofacial, and auditory problems. The typical skeletal dysplasia phenotype is marked by platyspondyly, irregular epiphyses, premature joint deterioration, joint laxity, and short trunk. In the eye, there is myopia and congenital vitreal anomalies predisposing to retinal detachment. Midface hypoplasia and cleft palate defects (including soft \pm hard palate, bifid, short uvula) and conductive and sensorineural hearing loss are other key clinical features. A type II collagen disorder could also underlie patients presenting with "isolated" PRS and should be considered.

\section{Type II collagen disorders can present in the prenatal period with lack of expected ossification of the skeleton} The most severe forms of type II collagen disorders are characterized by poor ossification of the axial skeleton in the prenatal period. In addition to very short tubular bones and short ribs, patients with achondrogenesis type II have absent or severely retarded ossification of the vertebral bodies and absent ossification of the sacrum. Iliac bones are small with crescent-shaped inner and inferior margins, and pubic and ischial bones have absent or severely delayed ossification. ${ }^{16}$ These children are usually delivered prematurely, either stillborn or dying within a few hours. In the slightly milder but also predominantly lethal hypochondrogenesis, vertebral bodies are small and ovoid, and unossified in the cervical region. Pubic bones are unossified and the ilia are hypoplastic. Short and relatively broad long bones are also seen. ${ }^{17}$ Most patients are born alive with subsequent demise from cardiorespiratory failure in the first few days to 3 months of life.

Mild to moderate type II collagen disorders can have less specific prenatal imaging features on ultrasound and magnetic resonance imaging (MRI). The moderately severe SEDC causes short extremities (less than 5th percentile) and delayed ossification of the spine, knee epiphyses, and pubic bones, creating a challenge to prenatal ultrasound diagnosis. ${ }^{18}$

Radiographic features of Stickler syndrome type I occur largely in childhood and beyond, however, micrognathia, cleft palate, and polyhydramnios on prenatal ultrasound have been reported in Stickler syndrome by Soulier et al. ${ }^{19}$

5. In the term neonate, coronal vertebral clefting, occipital defect posterior to the foramen magnum, absent distal femoral epiphyseal ossification, and absent ossification of the pubis are suggestive of type II collagen disorders

Coronal clefting is a vertical radiographic lucency within a vertebral body on lateral radiograph. Type II collagen disorders that demonstrate coronal clefting include Kniest dysplasia and Stickler syndrome. It is usually not seen in SEDC. ${ }^{20,21}$ Other skeletal dysplasias can display this finding including chondrodysplasia punctata, Desbuquois dysplasia, metatropic dysplasia, and Larsen syndrome. ${ }^{22}$

Although not reported in the literature, it is our collective experience that a focal radiolucency/defect in the inferior occiput posterior to the foramen magnum is often seen on lateral radiographs of the skull in neonates with type II collagen disorders such as SEDC, likely reflecting abnormal endochondral ossification.

Distal femoral and proximal tibial epiphyseal ossification centers should be visualized on radiographs in a term neonate. ${ }^{23}$ Type II collagen disorders including achondrogenesis type II, hypochondrogenesis, Kniest dysplasia, and SEDC are characterized by delayed epiphyseal ossification, and this feature is absent in the mildest type II collagen disorders.

Absent pubic ossification is seen in lethal and moderately severe type II collagen disorders, and absent ossification of the sacrum and ischial bones may also be seen.

The diagnosis of type II collagen disorder should be considered with any combination of these radiographic findings, particularly in the setting of short long bones, short trunk, or other key clinical features.

\section{Hypochondrogenesis is uniformly lethal during the perinatal period (nonconsensus)}

There was nonconsensus on this statement, likely due to the imprecise nature of the term "hypochondrogenesis," first described in 1983 by Maroteaux et al. ${ }^{24}$ The original case series highlighted four cases with the radiographic and clinical features as described in section 4 . One of the four survived the infant period and was reclassified as having "SEDC," creating the arbitrary distinction between hypochondrogenesis and SEDC based solely on survival. ${ }^{24,25}$ It is evident from its original description (and our personal experiences) that patients with radiographic features of hypochondrogenesis can survive. Whether they should be reclassified as SEDC, based solely on their survival, was not agreed upon.

\section{Neonates who present with PRS should have detailed} eye and audiological examination, looking for features of a type II collagen disorder, such as Stickler syndrome

PRS is a common craniofacial anomaly characterized by micrognathia, glossoptosis, and airway obstruction. A 
U-shaped cleft palate is often present. PRS may be isolated or part of a syndrome with other anomalies. Stickler syndrome type I is the most commonly associated condition and should be considered. ${ }^{26,27}$ A retrospective study of 115 patients with PRS revealed 21 (18.3\%) had Stickler syndrome as the underlying cause. ${ }^{28}$

\section{Children with type II collagen disorders may have average stature}

Type II collagenopathies that present with average stature include Czech dysplasia, Stickler syndrome, and mild SED with premature arthrosis. When patients lack dwarfism and have milder or absent limb and spine deformity, the diagnosis of a type II collagenopathy is challenging. These averagestatured patients may however display typical associated nonskeletal comorbidities of hearing loss, myopia with the risk of retinal detachment, palatal defects, and joint pain, with a radiographic appearance of precocious or inflammatory arthritis.

\section{There is no evidence that human growth hormone (hGH) supplementation in children with type II collagen disorders increases final height}

There was consensus that there is no evidence to support the use of hGH supplementation in children with type II collagenopathies. A study by Kanazawa et al. ${ }^{29}$ demonstrated no change in height or height velocity in two individuals with SED treated over a year.

10. Routine cardiac evaluation and surveillance (i.e., EKG, echocardiogram) is not indicated in patients with type II collagen disorders

There is no evidence that the incidence of congenital or acquired cardiac disease in patients with type II collagen disorders is increased compared with the general population. Mitral valve prolapse was reported to be more common in patients with Sticker syndrome, ${ }^{30}$ prompting recommendations for routine echocardiography. A large study of patients with molecularly confirmed Stickler syndrome ${ }^{31}$ showed no increase of mitral valve prolapse or other cardiac abnormalities. We do not recommend routine cardiac evaluation or surveillance of patients with type II collagen disorders, unless otherwise indicated.

\section{Significant respiratory problems are common in individuals with type II collagen disorders and need to be evaluated at all ages}

There was agreement that significant respiratory problems are common in type II collagen disorders. Manifestations of type II collagen abnormalities are seen throughout the respiratory system, including the midface and oropharynx, airways, lung parenchyma, and thorax. ${ }^{31,32}$ In general, the younger the presentation of a patient with a type II collagen disorder, the more likely that respiratory issue will be observed. In Terhal et al.'s series of 93 individuals with a type II collagen disorder, $26 \%$ had respiratory difficulties in the neonatal period including 8 with complications resulting from PRS. Other concerns in the more severely affected individuals include small chest, pulmonary hypoplasia, tracheobronchomalacia, and central apnea due to cervical instability. ${ }^{31}$

As infants grow, the development of kyphoscoliosis can impact respiratory function. Ongoing assessment and management of these issues is important and likely to require multiple specialists. Assessments may include physical examination, pulse oximetry, bronchoscopy, spirometry, sleep studies, and chest imaging. Treatment may include surgery for PRS, tracheostomy and mechanical ventilation, continuous positive airway pressure (CPAP), supplemental oxygen, bronchodilators, and prophylactic influenza and pneumococcal immunizations.

In adults with type II collagen conditions and short stature, sleep disordered breathing may be present. Sequelae of cleft palate repair may contribute to obstructive sleep apnea originating from the pharyngeal segment of the respiratory tree while tracheobronchomalacia may compromise subglottal airway patency (common in infancy/childhood). ${ }^{32}$ An unrecognized, unstable cervical spine may manifest as central sleep apnea. Sleep disordered breathing can be diagnosed with an overnight sleep study. Inclusion of end tidal $\mathrm{CO}_{2}$ and continuous pulse oximetry monitoring during the sleep study may demonstrate decreased pulmonary reserve. ${ }^{33}$ Depending on the severity of the spine involvement, the chest and lung volume may be small and further compromised by kyphosis and/or scoliosis.

Respiratory health in adults with a type II collagen condition with short stature is complex and requires the expertise of an adult pulmonologist to assess the extent and severity of pulmonary disease and direct treatment. Regular, lifetime follow up with a pulmonary physician, plus monitoring physical activity and lung capacity, is important to decrease morbidity and mortality. There is limited medical literature addressing pulmonary status of adults with average stature type II collagen conditions, but our experience suggests there are fewer issues with this cohort.

\section{Routine evaluation and surveillance by an ophthalmologist is necessary because the risk of retinal detachment and severe myopia is increased in type II collagen disorders}

Type II collagen is an important component of ocular vitreous humor and these disorders may show various eye abnormalities including myopia, vitreal changes, retinal detachment, lens subluxation, cataracts, and blindness. ${ }^{34-39}$ Depending on the location of the variant, there can be a high incidence of childhood retinal detachment and blindness. Variants in exon 2 of COL2A1 show extremely high rates, with $90 \%$ of patients manifesting significant eye disease by age 20 in one series. ${ }^{35}$ Stickler syndrome type I patients display myopia, vitreous degeneration, a high incidence of retinal detachment and retinal degeneration, foveal hypoplasia, ${ }^{40}$ posterior chorioretinal atrophy, and 
vitreoretinal degeneration. ${ }^{40}$ Patients with Kniest dysplasia display myopia, lens subluxations, retinal detachment, and other vitreal abnormalities. ${ }^{36}$

In type II collagen disorders, consensus was reached that an ophthalmologist should be involved at initial diagnosis and for ongoing surveillance due to the high incidence of serious eye problems. It is recommended such patients have a dilated exam with an expert ophthalmologist familiar with the range of issues and treatment options. New treatment options exist and are best offered before end-stage disease and/or blindness. $^{41-43}$

13. Patients with Stickler syndrome and confirmed COL2A1 variant should be considered for prophylactic retinopexy (nonconsensus)

Almost all Stickler syndrome type I patients have ocular abnormalities and over half have retinal detachment. ${ }^{44}$ Without surgical treatment, patients have a poor natural history with many progressing to blindness. From 1986 to 2003 one center found a complete retinal reattachment rate of $78.6 \%$ for all types of surgery in 30 eyes with improved visual acuity; ${ }^{42}$ another center had $100 \%$ reattachment in 16 eyes but noted need for multiple surgeries. ${ }^{45}$ Late presentation/poorer presenting visual acuity were associated with inferior longterm outcomes/poor visual acuity in both series, and recently prophylactic surgical intervention in Stickler syndrome has shown better outcomes.

In a series of 487 Stickler patients, comparisons were made between Cambridge prophylactic cryotherapy protocol treated eyes (293) and observed eyes (194) over 36 years. The therapy itself had no long-term complications and had a $9 \%$ postsurgical detachment rate over time, while in the observed group over half had retinal detachment (53.6\%), the majority occurring between 10 and 30 years. $^{42}$

A review of current prophylactic retinal therapy protocols in Stickler patients identified 360-degree cryotherapy and laser treatment as effective prophylactic retinopexy treatments with significant treatment effect compared with observation with no complications and high durability over time. ${ }^{46}$ In another series of 204 type I Stickler patients, observed eyes had $78 \%$ retinal detachment while prophylactic cryotherapy type retinopexy had a postsurgical detachment rate of $8 \%$ in bilaterally treated eyes and $10 \%$ in unilaterally treated eyes. ${ }^{47}$

We were unable to come to consensus on the recommendation for prophylactic retinopexy for individuals with type II collagen disorders. Nonetheless, there is literature to support its use, particularly in Stickler syndrome type I, as many children and adults present late with blindness or poor visual acuity persisting despite modern reattachment therapies. We recommend that patients with confirmed Stickler syndrome and $C O L 2 A 1$ variant be referred to a center that can offer prophylactic retinopexy. Disagreement in the group centered on whether this should be a routine procedure in all patients with Stickler syndrome type I, and is the reason why consensus for this recommendation was not reached (see Table 4).
14. Routine imaging and surveillance of the cervical spine is required in some type II collagen disorders (e.g., SEDC and Kniest) due to increased risk for instability and spinal cord compression. Imaging may include flexion-extension radiographs and MRI

Atlanto-axial instability with myelopathy can be seen in patients with severe SEDC, with incidence estimates varying between studies, and ranging from $28 \%$ to $43 \%$ (refs. ${ }^{31,48}$ ). We recommend routine flexion/extension radiographs of the cervical spine in all patients with or without symptoms in these more severe phenotypes (i.e., SEDC/Kniest). If there is no instability, reassess in 2-3 years, or if symptomatic. If there is instability with narrowing of the space available for the cord (SAC), an MRI of the cervical spine should be obtained in flexion and extension. In young children, delayed ossification in the upper cervical spine may limit the interpretation of the radiographs and an MRI in flexion and extension is warranted.

If the MRI demonstrates mild instability, defined as less than or equal to $5 \mathrm{~mm}$ of motion and a space available for the cord greater than $10 \mathrm{~mm}$, no myelomalacia, and an absence of symptoms, careful surveillance yearly is warranted. If there is cord compression, with or without myelomalacia, surgical intervention is recommended.

\section{Progressive kyphoscoliosis can occur in children with type II collagen disorders and should be clinically and radiographically monitored}

Kyphoscoliosis is common, often progressive, and can present in the early years of life. Serial radiographs (done standing) every 6 months should be done in children with progressive scoliosis. In small curves that are not progressing, yearly follow up is recommended. Progressive kyphoscoliosis may result in cord compression with upper motor neuron signs and bladder or bowel dysfunction. In those children with symptoms or signs of spinal cord compression, an entire spine MRI should be done. In addition, prior to any lower extremity surgery in children with kyphoscoliosis, an MRI should be done and spinal cord monitoring considered. Spinal cord injury has been reported in these children after extremity surgery. ${ }^{49}$

Treatment of kyphoscoliosis is typically a brace for mild curves and, if progressive, serial spine casting can be considered. Severe progressive kyphoscoliosis in a growing child should be treated with a growing rod system with final instrumentation and fusion when skeletally mature.

\section{Routine evaluation and surveillance for hearing loss is indicated in patients with type II collagen disorders}

Hearing loss is a feature of Kniest dysplasia, SEDC, and Stickler syndrome type I. Deafness can be sensorineural, conductive, or mixed. In Stickler syndrome, hearing loss is observed in $60 \%$ of cases. ${ }^{50-52}$ Deafness was observed in $75 \%$ of cases in an early description of Kniest dysplasia. ${ }^{53}$ In a series of 93 individuals with SEDC, 37\% were reported to have hearing loss. ${ }^{31}$ Because of the possibility of conductive hearing loss occurring in type II collagen disorders, hearing assessment at diagnosis and ongoing monitoring is indicated. 
17. Patients with type II collagen disorders may present with the appearance of bilateral Legg-Calvé-Perthes disease (LCPD)

Various hip pathologies are observed in patients with type II collagen disorders. It is common that femoral head ossification is severely delayed in these children. Once apparent, it appears small, stippled, and irregular in many patients. These epiphyses should normally become visualized radiographically at age $4-10$ months.

Legg-Calvé-Perthes disease (LCPD) is juvenile idiopathic osteonecrosis of the femoral head. It commences with spontaneous onset of limping, pain, and/or limitation of hip joint motion, most commonly at ages 4 to 8 years. It goes through avascular, resorption/fragmentation, and reossification stages, resulting in sequelae of various extent. ${ }^{54}$ The plain radiographic finding of irregular ossification of the femoral head in type II collagen disorders resembles that of the resorption/fragmentation stage of LCPD. This appearance is bilateral, symmetrical, and minimally progressive. It is sometimes confused with bilateral LCPD. Some other skeletal dysplasias involving the long bone epiphyses share the same problem of misdiagnosis of bilateral LCPD, including multiple epiphyseal dysplasia, pseudoachondroplasia, and the mucopolysaccharidoses. ${ }^{55-57}$

LCPD is bilaterally involved in only $10-15 \%$ cases, but the bilateral involvement is classically asynchronous, showing femoral heads in different stages of disease. Synchronous involvement of both hips with symmetrical findings favors diagnosis of a skeletal dysplasia rather than LCPD. While the femoral heads are never normally ossified in type II collagenopathy, LCPD is a progressive disease process affecting a well-ossified femoral head. Review of serial plain radiographs, if available, is an important exercise in determining this difference. LCPD usually manifests with hip pain, limitation of motion, or limp, whereas a type II collagenopathy does not usually have any clinical symptoms or signs in children. The avascular stage of LCPD can be well documented on MRI or bone scintigraphy and such studies for a type II collagenopathy would not reveal such findings.

It should be noted when seeing a patient with a type II collagenopathy, most commonly Stickler syndrome, that the femoral head may undergo genuine osteonecrosis. In this situation patients benefit from the therapeutic interventions applied to LCPD, such as rest, range of joint motion exercises, pain medication, and physiotherapy. Several specific COL2A1 variants have been reported in association with familial osteonecrosis of the femoral head in East Asia; however, screening for COL2A1 variants in 49 cases of idiopathic osteonecrosis of the femoral head failed to identify any patients with a COL $2 A 1$ variant. $^{58}$

\section{Patients with type II collagen disorders may present with early-onset arthritis}

Type II collagen is the primary structural component of the cartilage epiphysis and articular cartilage. Even if a defect of type II collagen does not interfere with endochondral ossification at the femoral head, it may still interfere with metabolism of the articular cartilage, affecting its durability and integrity.

Joint pain and limitation of motion to a various extent is common in patients with type II collagenopathy, before advancement to end-stage joint destruction. Symptoms maybe intermittent, progressive, spontaneous, or associated with strenuous physical activity. Weight-bearing joints such as the hip and knee are frequently affected with this morbidity. Although it is frequently referred to as "earlyonset osteoarthritis," the pathologic process in the beginning may not be a genuine inflammatory reaction because it rarely presents with joint swelling, local heat or elevation of acute phase reactants. The symptoms and signs in this phase may be caused by structural weakness and lack of integrity of articular cartilage, or by joint incongruity from the deformed epiphysis.

There have been several reports of type II collagenopathy presenting with premature osteoarthritis. ${ }^{13,14,58,59}$ The subjects showed well-ossified femoral heads, but suffered from progressive joint pain and limitation of motion at the hip and knee joints. The joint space on plain radiographs becomes narrower as the articular cartilage degenerates and thins out. Some patients became unable to bear weight and became wheelchair-bound.

\section{In type II collagen disorders, hip replacement can be a beneficial surgery for adolescents and young adults with early-onset arthritis}

As previously outlined, premature arthritis is common in type II collagen disorders, resulting from a combination of articular cartilage dysfunction, hypermobility, and the periarticular degeneration associated with epiphyseal dysplasia. ${ }^{11}$

Aside from overt arthritis, Rose et al. found that $79 \%$ of adults with Stickler syndrome reported hip pain and one-fifth of adults were medically disabled from musculoskeletal pain. ${ }^{12}$ One-third of the adult patients had osteoarthritis of the hip as defined by radiographic changes in conjunction with their hip pain. Further analysis revealed hip osteoarthritis in 7 of 10 Stickler syndrome patients older than age 50 and $34 \%$ of all skeletally mature patients, which are much greater than the general population. In a subset of patients who developed pediatric hip disease (6 of 38), all developed hip pain as adults. Three have had total joint arthroplasty at ages 15, 26, and 29, and two more, aged 18 and 37, were planning to undergo arthroplasty. Joint arthroplasty is clearly a viable option in young adults and adolescents with type II collagenopathy associated precocious arthritis. The comorbidities, anatomic constraints, and perioperative issues seen in these patients need to be thoroughly considered prior to proceeding. ${ }^{8}$

20. In type II collagen disorders with disproportionate short stature, coxa vara and genu valgum are frequently present Hip involvement in type II collagen disorders is very common with the typical deformity being coxa vara. The coxa vara is typically associated with limited hip abduction, hip flexion contractures, and external rotation contractures. This has an 
impact on gait and typically these children have a Trendelenburg gait, which becomes worse with fatigue. Progressive deformities are common and typically there is severe hip osteoarthritis by the 3 rd or 4 th decade.

Genu valgum is very common but knee alignment can be normal or rarely in varum. Knee realignment procedures (e.g., for recurrent genu valgum) will fail unless done in conjunction with hip realignment.

\section{Valgus extension/internal rotation osteotomy can improve gait in patients with coxa vara and type II collagen disorders}

There are very few studies that report the treatment of coxa vara in type II collagenopathies. ${ }^{60,61}$ All have been case series studies. A 2008 report using a hip support osteotomy with an external fixator reported improvements in hip pain, waddling gait, hip range of motion, and the Harris hip score. ${ }^{61}$ In a more recent article in 2017, valgus extension/internal rotation osteotomy was achieved with a femoral blade plate. This was an effective treatment that improved postoperative hip pain and hip range of motion as well as improved lumbar lordosis with a low recurrence rate. ${ }^{62}$

\section{Guided growth techniques (if sufficient growth} remains) and realignment osteotomies are effective in the treatment of severe genu valgum in children with type II collagen disorders

Guided growth techniques were considered to be appropriate in skeletally immature patients with type II collagen disorders. Correction of both varus and valgus deformity has been reported in many skeletal dysplasias, however there are no studies specific to type II collagen disorders. Yilmaz et al. ${ }^{63}$ did include four patients with SED, two with Kniest and one with Stickler syndrome. In this subset all but one patient demonstrated improvement in the mechanical axis deviation. For the 29 patients with skeletal dysplasia included, four patients with valgus and 3 patients with varus deformity did not benefit from the procedure. Three of these were over age 13 years. One 14-year-old girl with valgus deformity in her tibia had previous staple application on the same growth plate 3 years prior. One of the failures was in a patient with SED, age 14 years. The deformity recurrence risk in type II collagen disorders is not known.

\section{In patients with clinical or radiographic features of a} type II collagen disorder, molecular testing should be done to confirm diagnosis, allowing accurate recurrence risk counseling, prenatal diagnosis, and appropriate treatment options where available

If the characteristic features of a type II collagen disorder are recognized in a patient, molecular testing of COL $2 A 1$ should be pursued. Identification of a specific COL2A1 variant may improve anticipatory guidance, provide prenatal testing options, identify clinically unsuspected parents of clearly affected children via somatic mosaicism, and allow for accurate genetic counseling. Identification of the genetic etiology of the pleotropic manifestations of a type II collagen condition gives reassurance to the patient and provider that this is the cause of their clinical features, and that other genetic conditions with additional potential medical complications need not be considered further.

Variants in the COL $2 A 1$ gene are inherited in an autosomal dominant fashion with complete penetrance. If an affected individual wants to reduce his/her $50 \%$ risk of passing their type II collagen disorder on to each offspring, a variety of prenatal testing options are available to that person if their specific COL2A1 variant has been identified.

Somatic mosaicism for $C O L 2 A 1$ variants is well recognized in the medical literature to occur in $6-10 \%$ of parents of children with apparent germline mutations in this gene. ${ }^{31,64,65}$ Often the parent with somatic mosaicism has only subtle features to suggest a type II collagen disorder because of the reduced mutational burden in their body systems. A type II collagen disorder is considered only after their child, with an inherited germline variant in COL $2 A 1$, presents with more severe clinical features to suggest a classic type II collagenopathy. With confirmation of somatic mosaicism in a family, recurrence risk for the mosaic parent is modified to up to $50 \%$ for each offspring instead of assuming their affected child represented a spontaneous variant in COL2A1 with low recurrence risk.

\section{To promote socialization and independence, individuals with type II collagen disorders should be assessed for a mobility device for community distances}

A position paper published by the Rehabilitation Engineering and Assistive Technology Society of North America (RESNA) provides evidence supporting the use of power wheelchairs in children. ${ }^{66}$ Independent mobility positively affects many areas of typical development, including acquisition of social, emotional, cognitive, and perceptual skills. While power wheelchairs are commonly introduced to children with neuromuscular diseases, such as muscular dystrophy and spinal cord injury, the principle of early power chair use is applicable to genetic, metabolic, and syndrome disorders that compromise community participation. ${ }^{67}$ The loss of independent mobility, becoming unable to keep up with peers, or being challenged to travel distances quickly with minimal energy expenditure, adversely affect self-confidence and social maturation. A child's ability to drive a motorized wheelchair, scooter, or Segway is not related to chronologic age but to cognitive readiness, and children with type II collagenopathies are not intellectually impaired. We recommend that the clinical team consider introducing power wheelchairs to those with type II collagen skeletal dysplasias complicated by precocious arthritis, joint pain, and lower limb deformity that is limiting ambulation. Concurrent with implementation of adaptive equipment, it is essential to encourage as much physical activity as possible to avoid a sedentary lifestyle and obesity. 


\section{Conclusion}

Individuals with type II collagen disorders can present with myriad clinical features that require a rigorous approach with regard to their accurate diagnosis and subsequent successful multidisciplinary management. These consensus-based, expert best practice guidelines have been developed to assist clinicians to better understand, diagnose, and manage these conditions, to minimize associated health risks and improve clinical outcomes for their patients.

\section{DISCLOSURE}

M.B.B. is a consultant for Ascendis Pharma, BioMarin Pharmaceutical, QED Therapeutics, and Therachon; member of the Speaker's Bureau for Alexion Pharmaceuticals; and site principal investigator for Shire, BioMarin, Medlife Sciences, Osteogenesis Imperfecta (OI) Foundation, Growing Stronger Foundation, Walking With Giants Foundation, Potentials Foundation, and RhizoKids International. R.S. is a consultant for BioMarin, Ascendis, Alexion Pharmaceuticals, and QED Therapeutics. K.K. $W$. has received consulting fees, speaker's honoraria, travel reimbursement, and grant support from BioMarin Pharmaceuticals; speaker's honoraria and travel reimbursement from Genzyme; royalties from UpToDate.com; and grant support from Alexion and Ultragenyx. J. H.-F. is a paid consultant to BioMarin. This arrangement has been reviewed and approved by the Johns Hopkins University in accordance with its conflict of interest policies. W.G.M. is a member of the Little People of America Medical Advisory Board and MPS Medical Advisory Board and has received an honorarium from BioMarin. C.R. is a consultant to BioMarin, Ascendis, and Alexion and a member of the Ol Foundation Advisory Committee. The other authors declare no conflicts of interest.

Publisher's note: Springer Nature remains neutral with regard to jurisdictional claims in published maps and institutional affiliations.

\section{REFERENCES}

1. Yap $P$, Savarirayan R. Emerging targeted drug therapies in skeletal dysplasias. Am J Med Genet A. 2016;170:2596-2604.

2. Linstone $H$, Turoff $M$ The Delphi method. Addison-Wesley, Boston. 1975.

3. Fitch $K$, Bernstein $S$, Aguilar $M$, Burnand B The RAND/UCLA appropriateness method. RAND, Santa Monica. 2001.

4. Adler M, Ziglio E. Gazing into the oracle: the Delphi method and its applications to social policy and public health. London: Jessica Kingsley; 1996.

5. Stefanidis D, Cochran A, Sevdalis N, et al. Research priorities for multiinstitutional collaborative research in surgical education. Am J Surg. 2015;209:52-58.

6. Wong ST, Browne AJ, Varcoe C, et al. Development of health equity indicators in primary health care organizations using a modified Delphi. PLoS One. 2014;9:e114563.

7. Savarirayan R, Rossiter JP, Hoover-Fong JE, et al. Best practice guidelines regarding prenatal evaluation and delivery of patients with skeletal dysplasia. Am J Obstet Gynecol. 2018;219:545-562.

8. White KK, Bompadre V, Goldberg MJ, et al. Best practices in perioperative management of patients with skeletal dysplasias. Am J Med Genet A. 2017:173:2584-2595.

9. White KK, Bompadre V, Goldberg MJ, et al. Best practices in the evaluation and treatment of foramen magnum stenosis in achondroplasia during infancy. Am J Med Genet A. 2016;170a:42-51.
10. Kannu P, Bateman JF, Belluoccio D, Fosang AJ, Savarirayan R. Employing molecular genetics of chondrodysplasias to inform the study of osteoarthritis. Arthritis Rheum. 2009;60:325-334.

11. Nishimura G, Haga N, Kitoh $H$, et al. The phenotypic spectrum of COL2A1 mutations. Hum Mutat. 2005;26:36-43.

12. Rose PS, Ahn NU, Levy HP, et al. The hip in Stickler syndrome. J Pediatr Orthop. 2001;21:657-663.

13. Kannu P, Bateman JF, Randle $S$, et al. Premature arthritis is a distinct type II collagen phenotype. Arthritis Rheum. 2010;62:1421-1430.

14. Barat-Houari M, Dumont $B$, Fabre $A$, et al. The expanding spectrum of COL2A1 gene variants in 136 patients with a skeletal dysplasia phenotype. Eur J Hum Genet. 2016;24:992-1000.

15. Deng H, Huang X, Yuan L. Molecular genetics of the COL2A1-related disorders. Mutat Res Rev Mutat Res. 2016;768:1-13.

16. Spranger JW, Brill PW, Nishimura G. Superti-Furga A, Unger S. Achondrogenesis II. In: Spranger JW, Brill PW, Nishimura G, SupertiFurga A, Unger $S$, eds. Bone dysplasias: an atlas of genetic disorders of skeletal development. 3rd ed. New York: Oxford University Press; 2012. p. 127.

17. Spranger JW, Brill PW, Nishimura G, Superti-Furga A, Unger S. Hypochondrogenesis. In: Spranger JW, Brill PW, Nishimura G, SupertiFurga A, Unger $S$, eds. Bone dysplasias: an atlas of genetic disorders of skeletal development. 3rd ed. New York: Oxford University Press; 2012. p. 129.

18. Berceanu C, Gheonea IA, et al. Ultrasound and MRI comprehensive approach in prenatal diagnosis of fetal osteochondrodysplasias. Cases series. Med Ultrason. 2017;19:66-72.

19. Soulier M, Sigaudy S, Chau C, Philip N. Prenatal diagnosis of Pierre-Robin sequence as part of Stickler syndrome. Prenat Diagn. 2002;22:567-568.

20. Spranger JW, Brill PW, Nishimura G, Superti-Furga A, Unger S. Kniest dysplasia. In: Spranger JW, Brill PW, Nishimura G, Superti-Furga A, Unger S, (eds.) Bone dysplasias: an atlas of genetic disorders of skeletal development. 3rd ed New York: Oxford University Press; 2012. p. 139.

21. Spranger JW, Brill PW, Nishimura G, Superti-Furga A, Unger S. Stickler dysplasia. In: Spranger JW, Brill PW, Nishimura G, Superti-Furga A, Unger S, (eds.) Bone dysplasias: an atlas of genetic disorders of skeletal development. 3rd ed New York: Oxford University Press; 2012. p. 151-152.

22. Lachman RS. Taybi and Lachman's radiology of syndromes, metabolic disorders and skeletal dysplasias. 5th ed. Philadelphia, PA: Mosby Elsevier; 2007.

23. Coley BD. Caffey's pediatric diagnostic imaging. 12th ed. Philadelphia, PA: Elsevier Saunders; 2013. p. 1328-1329.

24. Maroteaux P, Stanescu V, Stanescu R. Hypochondrogenesis. Eur J Pediatr. 1983;141:14-22.

25. Castori M, Brancati F, Scanderbeg AC, Dallapiccola B. Hypochondrogenesis. Pediatr Radiol. 2006;36:460-461.

26. Basart H, Paes EC, Maas SM, et al. Etiology and pathogenesis of robin sequence in a large Dutch cohort. Am J Med Genet A. 2015;167A:1983-1992.

27. Breugem CC, Evans KN, Poets $C F$, et al. Best practices for the diagnosis and evaluation of infants with Robin sequence: a clinical consensus report. JAMA Pediatr. 2016;170:894-902.

28. Evans AK, Rahbar R, Rogers GF, Mulliken JB, Volk MS. Robin sequence: a retrospective review of 115 patients. Int J Pediatr Otorhinolaryngol. 2006;70:973-980.

29. Kanazawa $H$, Tanaka H, Inoue M, Yamanaka $Y$, Namba N, Seino $Y$. Efficacy of growth hormone therapy for patients with skeletal dysplasia. J Bone Miner Metab. 2003;21:307-310.

30. Liberfarb RM, Hirose T, Holmes LB. The Wagner-Stickler syndrome: a genetic study. Birth Defects Orig Artic Ser. 1979;15:145-154.

31. Terhal PA, Nievelstein RJ, Verver EJ, et al. A study of the clinical and radiological features in a cohort of 93 patients with a COL2A1 mutation causing spondyloepiphyseal dysplasia congenita or a related phenotype. Am J Med Genet A. 2015;167a:461-475.

32. Harding CO, Green CG, Perloff WH, Pauli RM. Respiratory complications in children with spondyloepiphyseal dysplasia congenita. Pediatr Pulmonol. 1990;9:49-54.

33. Ross KR, Rosen CL. Sleep and respiratory physiology in children. Clin Chest Med. 2014;35:457-467.

34. Kannu P, Bateman J, Savarirayan R. Clinical phenotypes associated with type II collagen mutations. J Paediatr Child Health. 2012;48:E38-43.

35. Donoso LA, Edwards AO, Frost AT, et al. Clinical variability of Stickler syndrome. Surv Ophtalmol. 2003;48:191-203. 
36. Sergouniotis PI, Fincham GS, McNinch AM, et al. Ophthalmic and molecular genetic findings in Kniest dysplasia. Eye (Lond). 2015;29:475-482.

37. Edwards $\mathrm{TL}$, Burt $\mathrm{BO}$, Black $\mathrm{GC}$, et al. Familial retinal detachment associated with COL2A1 exon 2 and FZD4 mutations. Clin Exp Ophthalmol. 2012;40:476-483.

38. Snead MP, McNinch AM, Poulson AV, et al. Stickler syndrome, ocularonly variants and a key diagnostic role for the ophthalmologist. Eye (Lond). 2011;25:1389-1400.

39. Meredith SP, Richards AJ, Bearcroft P, Pouson AV, Snead MP. Significant ocular findings are a feature of heritable bone dysplasias resulting from defects in type II collagen. Br J Ophthalmol. 2007;91:1148-1151.

40. Matsushita I, Nagata T, Hayashi T, et al. Foveal hypoplasia in patients with Stickler syndrome. Ophthalmology. 2017;124:896-902.

41. Vu CD, Brown J Jr, Korkko J, Ritter R 3rd, Edwards AO. Posterior chorioretinal atrophy and vitreous phenotype in a family with Stickler syndrome from a mutation in the COL2A1 gene. Ophthalmology. 2003;110:70-77.

42. Fincham GS, Pasea L, Carroll C, et al. Prevention of retinal detachment in Stickler syndrome: the Cambridge prophylactic cryotherapy protocol. Ophthalmology. 2014;121:1588-1597.

43. Abeysiri P, Bunce C, da Cruz L. Outcomes of surgery for retinal detachment in patients with Stickler syndrome: a comparison of two sequential 20-year cohorts. Graefes Arch Clin Exp Ophthalmol. 2007:245:1633-1638.

44. Antunes RB, Alonso N, Paula RG. Importance of early diagnosis of Stickler syndrome in newborns. J Plast Reconstr Aesthet Surg. 2012;65:1029-1034.

45. Reddy DN, Yonekawa Y, Thomas BJ, Nudleman ED, Williams GA. Longterm surgical outcomes of retinal detachment in patients with Stickler syndrome. Clin Ophthalmol. 2016;10:1531-1534.

46. Carroll C, Papaioannou D, Rees A, Kaltenthaler E. The clinical effectiveness and safety of prophylactic retinal interventions to reduce the risk of retinal detachment and subsequent vision loss in adults and children with Stickler syndrome: a systematic review. Health Technol Assess. 2011;15:iii-xiv, 1-62.

47. Ang A, Poulson AV, Goodburn SF, Richards AJ, Scott JD, Snead MP. Retinal detachment and prophylaxis in type 1 Stickler syndrome. Ophthalmology. 2008;115:164-168.

48. Miyoshi K, Nakamura K, Haga N, Mikami Y. Surgical treatment for atlantoaxial subluxation with myelopathy in spondyloepiphyseal dysplasia congenita. Spine. 2004;29:E488-91.

49. Pruszczynski B, Mackenzie WG, Rogers K, White KK. Spinal cord injury after extremity surgery in children with thoracic kyphosis. Clin Orthop Relat Res. 2015;473:3315-3320.

50. Acke FR, Dhooge IJ, Malfait F, De Leenheer EM. Hearing impairment in Stickler syndrome: a systematic review. Orphanet J Rare Dis. 2012;7:84.

51. Admiraal RJ, Szymko YM, Griffith AJ, Brunner HG, Huygen PL. Hearing impairment in Stickler syndrome. Adv Otorhinolaryngol. 2002;61:216-223.

52. Szymko-Bennett YM, Mastroianni MA, Shotland LI, et al. Auditory dysfunction in Stickler syndrome. Arch Otolaryngol Head Neck Surg. 2001;127:1061-1068.
53. Siggers CD, Rimoin DL, Dorst JP, Doty SB, Williams BR, Hollister DW, et al. The Kniest syndrome. Birth Defects Orig Artic Ser. 1974;10:193-208.

54. Kim H, Herring J. Legg-Calve-Perthes disease. In: Herring JA, Tachdjian's pediatric orthopaedics. Philadelphia, PA: Elsevier Saunders; 2014, 385-406.

55. Crossan JF, Wynne-Davies R, Fulford GE. Bilateral failure of the capital femoral epiphysis: bilateral Perthes disease, multiple epiphyseal dysplasia, pseudoachondroplasia, and spondyloepiphyseal dysplasia congenita and tarda. J Pediatr Orthop. 1983;3:297-301.

56. Andersen PE Jr., Schantz K, Bollerslev J, Justesen P. Bilateral femoral head dysplasia and osteochondritis. Multiple epiphyseal dysplasia tarda, spondylo-epiphyseal dysplasia tarda, and bilateral Legg-Perthes disease. Acta Radiol. 1988;29:705-709.

57. Mendelsohn NJ, Wood T, Olson RA, et al. Spondyloepiphyseal dysplasias and bilateral Legg-Calve-Perthes disease: diagnostic considerations for mucopolysaccharidoses. JIMD Rep. 2013;11:125-132.

58. Sakamoto $Y$, Yamamoto T, Miyake N, Matsumoto N, lida A, Nakashima $Y$, et al. Screening of the COL2A1 mutation in idiopathic osteonecrosis of the femoral head. J Orthop Res. 2017;35:768-774.

59. Carlson KM, Yamaga KM, Reinker KA, Hsia YE, Carpenter C, Abe LM, et al. Precocious osteoarthritis in a family with recurrent COL2A1 mutation. J Rheumatol. 2006;33:1133-1136.

60. Oh CW, Thacker MM, Mackenzie WG, Riddle EC. Coxa vara: a nove measurement technique in skeletal dysplasias. Clin Orthop Relat Res. 2006;447:125-131.

61. Shetty GM, Song HR, Lee SH, Kim TY. Bilateral valgus-extension osteotomy of hip using hybrid external fixator in spondyloepiphyseal dysplasia: early results of a salvage procedure. J Pediatr Orthop B. 2008; 17:21-25

62. Bayhan IA, Abousamra O, Rogers KJ, Bober MB, Miller F, Mackenzie WG Valgus hip osteotomy in children with spondyloepiphyseal dysplasia congenita: midterm results. J Pediatr Orthop. 2017, Epub 30 Jan 2017. https://doi.org/10.1097/BPO0000945.

63. Yilmaz G, Oto M, Thabet AM, Rogers KJ, Anticevic D, Thacker MM, et al. Correction of lower extremity angular deformities in skeletal dysplasia with hemiepiphysiodesis: a preliminary report. J Pediatr Orthop. 2014;34:336-345.

64. Winterpacht A, Hilbert M, Schwarze U, Mundlos S, Spranger J, Zabel BU. Kniest and Stickler dysplasia phenotypes caused by collagen type II gene (COL2A1) defect. Nat Genet. 1993;3:323-326.

65. Spranger J, Menger $H$, Mundlos S, Winterpacht A, Zabel B. Kniest dysplasia is caused by dominant collagen II (COL2A1) mutations: parental somatic mosaicism manifesting as Stickler phenotype and mild spondyloepiphyseal dysplasia. Pediatr Radiol. 1994;24:431-435.

66. Rosen L, Arva J, Furumasu J, Harris M, Lange ML, McCarthy E, et al. RESNA position on the application of power wheelchairs for pediatric users. Assist Technol. 2009;21:218-225.

67. De Souza LH, Frank AO. Rare diseases: matching wheelchair users with rare metabolic, neuromuscular or neurological disorders to electric powered indoor/outdoor wheelchairs (EPIOCS). Dis Rehab. 2016;38:1547-1556. 